\title{
HUBUNGAN SUPERVISI PENGAJARAN AGAMA HINDU DENGAN KINERJA GURU AGAMA HINDU YANG BERSERTIFIKAT PENDIDIK DI SEKOLAH DASAR SE-KECAMATAN PENEBEL
}

\author{
Oleh \\ I Made Wiguna Yasa \\ wigunayasa@yahoo.com \\ Institut Hindu Dharma Negeri Denpasar
}

\begin{abstract}
Abstrak
Guna mewujudkan tujuan pendidikan nasional guru memegang peran dan tanggungjawab yang sangat penting sebagai pelaksana sistem pendidikan, untuk mengemban tanggung jawab tersebut, guru harus memiliki kinerja yang tinggi. Tinggi rendahnya kinerja guru dapat dipengaruhi oleh faktor internal dan faktor eksternal.Penelitian ini bertujuan untuk melihat hubungan Supervisi Pengajaran dengan Kinerja Guru Agama Hindu yang bersertifikat Pendidik di Sekolah Dasar Se- Kecamatan Penebel. Populasi penelitian adalah 46 orang Guru Agama Hindu yang bersertifikat Pendidik di Sekolah Dasar Se- Kecamatan Penebel dan masih aktif bertugas. Pengumpulan data digunakan kuesioner model skala Likert lima pilihan. Untuk menganalisis data digunakan analisis jalur (Path analisis). Hasil penelitian menunjukkan bahwa: Ada hubungan yang signifikan secara langsung antara supervisi pengajaran guru dengan kinerja guru Agama Hindu yang bersertifikat Pendidik di Sekolah Dasar se-Kecamatan Penebel, diperoleh koefisien beta sebesar 0,135 dan probabilitasnya 0,000<00,5.
\end{abstract}

\section{Kata kunci : Supervisi Pengajaran Agama Hindu, Kinerja Guru}

\section{PENDAHULUAN}

Pendidikan

Nasional

sebagaimana yang diamanatkan dalam Undang-Undang Sistem Pendidikan Nasional No 20 Tahun 2003 mengatakan bahwa, Pendidikan Nasional berdasarkan Pancasila dan Undang-Undang Dasar tahun 1945, memiliki fungsi dan tujuan mengembangkan kemampuan dan membentuk watak serta peradaban bangsa yang bermartabat dalam rangka mencerdaskan kehidupan bangsa. Tujuannya mengembangkan potensi agar menjadi manusia yang beriman dan bertakwa kepada Tuhan Yang Maha Esa, berakhlak mulia, sehat, berilmu, cakap, kreatif, mandiri, dan menjadi warga Negara yang demokratis serta bertanggung jawab. Hal ini, menjadi tugas berat bagi penyelenggara pendidikan khususnya sekolah sebagai unit pelaksana teknis di lapangan.

Untuk mewujudkan cita-cita pembangunan bidang pendidikan kementerian Pendidikan dan Kebudayaan (Kemendikbud) sebagai lembaga yang bertanggung jawab dalam pengelolaan pendidikan nasional telah menetapkan beberapa kebijakan sebagai acuan normatif dalam menerapkan sistem pendidikan nasional secara kongkret. Untuk mewujudkan hal tersebut telah merumuskan Visi pendidikan nasional sebagai berikut : 
Visi pendidikan nasional adalah terwujudnya sistem pendidikan sebagai pranata yang kuat dan berwibawa untuk memberdayakan semua warga negara Indonesia berkembang menjadi manusia yang berkualitas, sehingga mampu dan proaktif menjawab tantangan zaman yang selalu berubah (Depdiknas, 2006: 3).

Untuk mewujudkan Visi tersebut Kemendiknas merumuskan misinya sebagai berikut : (1) meningkatkan ketersediaan layanan pendidikan, (2) memperluas keterjangkauan layanan pendidikan, (3) meningkatkan kualitas /mutu layanan pendidikan, ( 4) mewujudkan kesetaraan dalam memperoleh layanan pendidikan dan (5) menjamin kepastian dalam memperoleh layanan pendidikan (Depdiknas, 2006 : 4).

Untuk mewujudkan pembangunan dibidang pendidikan Pemerintah telah menetapkan kebijakan sebagai arah dalam upaya meningkatkan kualitas proses pembelajaran pada setiap mata pelajaran, sesuai dengan maksud dan tujuan yang harus dicapai. PP No. $13 / 2015$ tetang standar nasional Pendidikan menyatakan bahwa “ Kurikulum untuk jenis pendidikan umum, kejuruan dan khusus pada jenjang Pendidikan dasar dan Menengah terdiri atas,(a) Kelompok mata pelajaran agama dan akhlak mulia, (b) kelompok mata pelajaraan kewarganegaraan dan kepribadian, (c) kelompok mata pelajaran ilmu pengetahuan dan tehnologi, (d) kelompok mata pelajaran estetika, (e) kelompok mata pelajaran jasmani, olah raga dan kesehatan “ ( PP. 13/2015 pasal 64).
Masing-masing

mata pelajaran dikelola oleh guru sesuai bidang keahliannya, guru pendidikan agama Hindu bertanggung jawab terhadap terlaksananya proses pembelajaran pendidikan Agama Hindu pada jenjang dan satuan pendidikan masing-masing sesuai tugas dan fungsinya untuk mewujudkan pendidikan mata pelajaran Agama Hindu. Pendidikan Agama Hindu memiliki peran sangat penting dalam kehidupan umat manusia.Agama menjadi pemandu dalam upaya untuk mewujudkan suatu kehidupan yang bermakna, damai dan martabat. Di dalam Peraturan Menteri Pendidikan Nasional No.22 tahun 2006 (Permen, 22 / 2006 ) tentang standar isi untuk satuan Pendidikan Dasar dan Menengah dinyatakan bahwa :

Pendidikan Agama dimaksudkan untuk membentuk peserta didik menjadi manusia yang beriman dan bertaqwa kepada Tuhan Yang Maha Esa dan berhaklak mulia serta peningkatan potensi spritual. Aklhak mulia mecangkup Etika, Budi pakerti dan moral,sebagai perujudan dari pendidikan agama. Peningkatan potensi sepiritual mencangkup pengenalan, nilai-nilai tersebut dalam kehidupan individu ataupun kolektif kemasyarakatan. Peningkatan nilai spiritual tersebut akhirnya bertujuan pada optimalisasi berbagai potensi berbagai potensi yang dimiliki manusia yang aktualisasinya mencerminkan harkat dan martabatnya sebagai mahluk Tuhan.

$\begin{array}{lrr} & \text { Kinerja } & \text { Guru adalah tenaga } \\ \text { profesional yang } & \text { mampu } \\ \text { menjalankan pekerjaannya } & \text { sesuai } \\ \text { dengan tuntutan profesi. } & \text { Seorang } \\ \text { guru yang profesional } & \text { dalam }\end{array}$


melaksanakan tugas, harus mampu menunjukkan sikap menjunjung tinggi karier dengan menjaga citra profesinya. Disamping itu, memiliki tiga bidang tugas utama yaitu: (1) bidang profesi, seorang guru profesional berfungsi untuk mengajar, mendidik, melatih dan melaksanakan penelitian masalahmasalah kependidikan, (2) bidang kemanusiaan, guru profesional berfungsi sebagai pengganti orang tua, khususnya dalam bidang kemampuan intelektual peserta didik, guru profesional menjadi fasilatator untuk membantu peserta didik memiliki kemampuan serta keterampilan yang berkembang dan bermanfaat bagi kemanusiaan, dan (3) bidang kemasyarakatan, profesi guru berfungsi untuk memenuhi amanat UUD 1945 yaitu ikut serta dalam mencerdaskan kehidupan Bangsa Indonesia (Sahabudin, Tilaar: 2002)

Untuk mendukung upaya peningkatan profesional guru, faktor yang tidak boleh diabaikan adalah Pengawasan atau supervisi. Pengawasan atau supervisi merupakan kegiatan atau serangkaian usaha pemberian bantuan kepada guru dalam upaya memajukan pendidikan. Pidarta (1999:12) menyebutkan bahwa, supervisi pengajaran adalah satu-satunya usaha pembinaan guru-guru yang tetap ajeg, dalam arti dilakukan secara kontinu, dan relatif untuk semua guru. Kemudian diuraikan pula bahwa supervisi dilaksanakan dan diarahkan pada hal-hal yang bersifat teknis operasional dalam bidang pendidikan, yaitu guna terlaksananya peningkatan atau proses pembelajaran yang efektif, efisien dan relevan. Nilai supervisi terletak pada perbaikan prosedur pengajaran yang dicerminkan pada pengembangan siswa.

Sahertian

(2008:12)

mengatakan supervisi bertujuan memberikan layanan dan bantuan untuk meningkatkan kualitas mengajar guru di kelas yang pada gilirannya untuk meningkatkan kualitas belajar siswa, bukan saja memperbaiki kinerja mengajar tetapi juga untuk mengembangkan kualitas guru. Supervisi memiliki dasar yang kuat bagi strategi pembinaan profesional guru. Ada dua alasan yang menguatkannya. Pertama supervisi memiliki prosedur. Jadi untuk pembinaan memerlukan proses ada langkah-langkah yang diacunya. Kedua supervisi sebagai konsep pembinaan. Ada tujuh elemen konseptual, yaitu: (1) supervisi adalah perlakuaan yang disengaja dengan proses pembelajaran, karena dirancang untuk hal itu, (2) menekankan penciptaan produktifitas, baik bagi guru maupun supervisor, (3) mempersyaratkan pengetahuan dan pelatihan bagi para supervisor, (4) supervisi adalah suatu tehnologi untuk perbaikan dan peningkatan pembelajaran siswa dan pengajaran guru, (5) sifatnya berorientasi pada tujuan, sistimatik dan luwes, (6) mepersyaratkan saling percaya dan pemeliharaan hubungan, dan (7) membantu penjelasan dan menggabarkan peranan masingmasing bentuk layanan profesional yang diberikan oleh supervisor (pengawas sekolah, kepala sekolah dan pembina lainnya) guna meningkatkan mutu proses dan hasil belajar mengajar. Supervisi atau pembinaan guru tersebut lebih menekankan pada pembinaan profesional guru yakni pembinaan 
yang lebih diarahkan pada upaya memperbaiki dan meningkatkan kinerja profesional guru (Sahertian :2008 : 14).

Berdasarkan latar belakang di atas, maka perlu ditelaah secara lebih mendalam melalui suatu penelitian terhadap Hubungan Supervisi Pengajaran Agama Hindu dengan kinerja guru Agama Hindu. Penelitian ini bertujuan untuk melihat hubungan Supervisi Pengajaran Agama Hindu dengan Kinerja Guru Agama Hindu yang bersertifikat Pendidik di Sekolah Dasar Se- Kecamatan Penebel.

\section{PEMBAHASAN}

\section{Kinerja Guru Agama Hindu (Y)}

Kinerja guru adalah gambaran hasil kerja yang dilakukan seorang guru atau dengan kata lain kinerja adalah unjuk kerja seorang guru. Unjuk kerja tersebut terkait dengan tugas apa yang diemban oleh seorang guru yang merupakan tanggung jawab profesionalnya, yang ditunjukkan oleh skor yang dicapai seorang guru dalam menjawab kuesioner kinerja guru dan data yang diperoleh berupa skala interval. Enam kriteria yang dapat digunakan untuk mengukur kinerja guru, yaitu (1) Quality, (2) Quantity, (3) Timeliness, (4) Cost-effectivenes, (5) Need for supervision, dan (6) Interpersonal impact.

\section{Supervisi Pengajaran (X)}

Secara konseptual, supervisi pengajaran merupakan serangkaian kegiatan atau upaya membantu guru dalam mengembangkan kemampuannya, mengelola proses belajar mengajar demi pencapaian tujuan pengajaran. Dengan demikian, esensi dari supervisi pengajaran adalah memberi bantuan kepada guru agar dapat mengembangkan kemampuan profesionalnya. Supervisi adalah bantuan dalam pengembangan situasi belajarmengajar agar memperoleh kondisi yang lebih baik. Meskipun tujuan akhirnya tertuju pada hasil belajar siswa, namun yang diutamakan dalam supervisi adalah bantuan kepada guru, tentu akhirnya berdampak pada siswa pula. Guru memegang peran penting dalam pembelajaran siswa, supervisi tidak lain dari usaha memberi layanan kepada guru-guru baik secara individual maupun secara kelompok dalam usaha memperbaiki pengajaran. Kata kunci dari pemberi supervisi pada akhirnya ialah memberikan layanan dan bantuan.

\section{Instrumen Penelitian}

Instrumen merupakan alat bantu bagi peneliti dalam menggunakan metode pengumpulan data. Instrumen selain untuk mengumpulkan data dapat juga digunakan untuk mengukur variabel penelitian. Instrumen yang digunakan dalam pengumpulan data penelitian adalah kuesioner, yaitu daftar pertanyaan yang harus dijawab oleh orang yang menjadi sampel penelitian. Setiap metode pengumpulan data tidak luput dari kebaikan dan kelemahan. Demikian pula halnya dengan kuesioner Intrumen pada umumnya perlu mempunyai dua syarat penting, yaitu valid dan reliabel. Untuk mendapatkan kelompok data dipergunakan instrumen. Instrumen dalam bentuk angket terbuka/ daftar pertanyaan dikontruksi sendiri oleh peneliti.

\section{UJI VALIDITAS}

a. Uji Validitas 
1) Variabel Kinerja Guru Agama Hindu

Setelah dilakukan uji coba validitas pada variabel Kinerja Guru Agama Hindu dengan jumlah kuesioner 33 butir dan jumlah responden 46 orang yang menggunakan korelasi product moment diperoleh angka validitas seperti berikut ini.

\section{Uji Validitas Variabel Kinerja Guru Agama Hindu}

\begin{tabular}{|c|c|c|c|}
\hline No & $\mathbf{r}_{\text {hitung }}$ & $\mathbf{r}_{\text {tabel }}$ & Keputusan \\
\hline 1 & 0,910 & 0,291 & Valid \\
\hline 2 & 0,881 & 0,291 & Valid \\
\hline 3 & 0,805 & 0,291 & Valid \\
\hline 4 & 0,980 & 0,291 & Valid \\
\hline 5 & 0,916 & 0,291 & Valid \\
\hline 6 & 0,950 & 0,291 & Valid \\
\hline 7 & 0,948 & 0,291 & Valid \\
\hline 8 & 0,729 & 0,291 & Valid \\
\hline 9 & 0,805 & 0,291 & Valid \\
\hline 10 & 0,928 & 0,291 & Valid \\
\hline 11 & 0,923 & 0,291 & Valid \\
\hline 12 & 0,939 & 0,291 & Valid \\
\hline 13 & 0,895 & 0,291 & Valid \\
\hline 14 & 0,881 & 0,291 & Valid \\
\hline 15 & 0,805 & 0,291 & Valid \\
\hline 16 & 0,904 & 0,291 & Valid \\
\hline 17 & 0,881 & 0,291 & Valid \\
\hline 18 & 0,805 & 0,291 & Valid \\
\hline
\end{tabular}

http://ejournal.ihdn.ac.id/index.php/AW

\begin{tabular}{|c|c|c|c|}
\hline No & $\mathbf{r}_{\text {hitung }}$ & $\mathbf{r}_{\text {tabel }}$ & Keputusan \\
\hline 19 & 0,793 & 0,291 & Valid \\
\hline 20 & 0,890 & 0,291 & Valid \\
\hline 21 & 0,906 & 0,291 & Valid \\
\hline 22 & 0,831 & 0,291 & Valid \\
\hline 23 & 0,979 & 0,291 & Valid \\
\hline 24 & 0,915 & 0,291 & Valid \\
\hline 25 & 0,953 & 0,291 & Valid \\
\hline 26 & 0,939 & 0,291 & Valid \\
\hline 27 & 0,829 & 0,291 & Valid \\
\hline 28 & 0,919 & 0,291 & Valid \\
\hline 29 & 0,906 & 0,291 & Valid \\
\hline 30 & 0,906 & 0,291 & Valid \\
\hline 31 & 0,863 & 0,291 & Valid \\
\hline 32 & 0,891 & 0,291 & Valid \\
\hline 33 & 0,812 & 0,291 & Valid \\
\hline
\end{tabular}

Setelah dilakukan pengujian, maka diperoleh hasil uji validitas butir instrumen Kinerja Guru agama Hindu dengan bantuan program SPSS for Windows versi 16.00 menunjukkan bahwa 33 butir instrumen valid. 33 Butir instrumen kinerja guru agama Hindu yang valid dianggap cukup untuk menjaring data penelitian.

2) Variabel Supervisi Pengajaran Agama Hindu

Setelah dilakukan uji coba validitas pada Supervisi pengajaran agama Hindu dengan jumlah kuesioner 33 butir dan jumlah responden 46 orang yang 
menggunakan korelasi product moment diperoleh angka validitas seperti berikut ini : Uji Validitas Variabel Supervisi
Pengajaran Agama Hindu

\begin{tabular}{|c|c|c|c|}
\hline No & $\mathbf{r}_{\text {hitung }}$ & $\mathbf{r}_{\text {tabel }}$ & Keputusan \\
\hline 1 & 0,902 & 0,291 & Valid \\
\hline 2 & 0,881 & 0,291 & Valid \\
\hline 3 & 0,976 & 0,291 & Valid \\
\hline 4 & 0,989 & 0,291 & Valid \\
\hline 5 & 0,989 & 0,291 & Valid \\
\hline 6 & 0,989 & 0,291 & Valid \\
\hline 7 & 0,873 & 0,291 & Valid \\
\hline 8 & 0,975 & 0,291 & Valid \\
\hline 9 & 0,976 & 0,291 & Valid \\
\hline 10 & 0,989 & 0,291 & Valid \\
\hline 11 & 0,989 & 0,291 & Valid \\
\hline 12 & 0,989 & 0,291 & Valid \\
\hline 13 & 0,989 & 0,291 & Valid \\
\hline 14 & 0,881 & 0,291 & Valid \\
\hline 15 & 0,976 & 0,291 & Valid \\
\hline 16 & 0,989 & 0,291 & Valid \\
\hline 17 & 0,885 & 0,291 & Valid \\
\hline 18 & 0,976 & 0,291 & Valid \\
\hline 19 & 0,898 & 0,291 & Valid \\
\hline 20 & 0,989 & 0,291 & Valid \\
\hline
\end{tabular}

http://ejournal.ihdn.ac.id/index.php/AW

\begin{tabular}{|c|c|c|c|}
\hline No & $\mathbf{r}_{\text {hitung }}$ & $\mathbf{r}_{\text {tabel }}$ & Keputusan \\
\hline 21 & 0,870 & 0,291 & Valid \\
\hline 22 & 0,691 & 0,291 & Valid \\
\hline 23 & 0,989 & 0,291 & Valid \\
\hline 24 & 0,989 & 0,291 & Valid \\
\hline 25 & 0,989 & 0,291 & Valid \\
\hline 26 & 0,989 & 0,291 & Valid \\
\hline 27 & 0,701 & 0,291 & Valid \\
\hline 28 & 0,938 & 0,291 & Valid \\
\hline 29 & 0,989 & 0,291 & Valid \\
\hline 30 & 0,989 & 0,291 & Valid \\
\hline 31 & 0,989 & 0,291 & Valid \\
\hline 32 & 0,870 & 0,291 & Valid \\
\hline 33 & 0,989 & 0,291 & Valid \\
\hline
\end{tabular}

Setelah dilakukan pengujian, maka hasil uji validitas butir instrumen Supervisi pengajaran agama Hindu dengan bantuan program SPSS for Windows versi 16.00 menunjukkan bahwa 33 butir instrumen dinyatakan valid. 33 Butir instrumen Supervisi pengajaran agama Hindu yang valid dianggap cukup untuk menjaring data penelitian.

b. Uji Reliabilitas

Reliabilitas angket instrumen Kinerja guru Agama Hindu dihitung dengan menggunakan koefisien alpha. Dari hasil perhitungan, diperoleh koefisien alpha sebesar 0,991. Angka ini menunjukkan bahwa instrumen kinerja Guru Agama Hindu mempunyai keterandalan yang sangat tinggi sehingga layak digunakan dalam penelitian. 
Reliabilitas angket instrumen Supervisi pengajaran agama Hindu dihitung dengan menggunakan koefisien alpha. Dari hasil perhitungan, diperoleh koefisien alpha sebesar 0,996. Angka ini menunjukkan bahwa instrumen supervise pengajaran agama Hindu mempunyai keterandalan yang sangat tinggi sehingga layak digunakan dalam penelitian.

\section{F. Uji Persyaratan Analisis (Uji Asumsi)}

Uji asumsi atau uji persyaratan analisis ini merupakan prasyarat bagi penerapan analisis statistik inferensial-parametrik. Uji prasyarat ini adalah untuk mengetahui apakah data yang diperoleh telah memenuhi syarat untuk dianalisis dengan menggunakan tehnik parametrik. Untuk persyaratan yang menyatakan bahwa variabel-variabel yang akan dianalisis berasal dari data yang berskala interval, tidak perlu diuji karena data yang telah diperoleh berskala interval. Karena itu, uji asumsi yang dicari, antara lain: (1) uji normalitas, (2) uji multikolinearitas antar variabel bebas, (3) uji linearitas hubungan, dan (4) uji heteroskedastisitas varians.

\section{G. Uji Analisis Jalur (path analysis)}

Teknik statistik ini merupakan pengembangan lebih lanjut dari Regresi Ganda. Jika dalam Regresi Ganda semua variabel bebas berderet sederajat dalam satu blok, sementara dalam analsisis jalur, variabel bebas terbagi ke dalam beberapa blok yang tersusun dapat diketahui akibat langsung dan akibat tidak langsung antar variabel (Asher,1983). Akibat langsung
http://ejournal.ihdn.ac.id/index.php/AW

berarti arah hubungan antara dua variabel langsung tanpa melewati variabel lain, sementara hubungan tidak langsung harus melewati variabel lain. Oleh sebab itu, untuk menentukan arah hubungan antar variabel, harus disusun model teoritik yang didasarkan pada bahasan teori. Model teoritik penelitian ini diujikan secara empirik di lapangan. Signifikansi yang tampak didasarkan pada hasil koefisien beta (b) pada setiap jalur. Dengan analisis jalur ini juga dapat diestimasi besarnya hubungan kausal antara sejumlah jalur-jalur hubungan kausal baik hubungan langsung maupun tidak langsung (Hasan, 1992, Asher, 1983, Cohen dan Cohen, 1983).

\section{H. Deskripsi Data Variabel Supervisi Pengajaran Agama Hindu}

Berdasarkan data penelitian untuk skor kinerja guru Pendidikan Agama Hindu, memiliki skor riil terkecil 99 dan skor terbesar 142 dari sekor terendah yang mungkin dicapai ( skor minimal idal) 33 dan sekor tertinggi yang mungkin tercapai (skor maksimal edial) 165. dari skor tersebut diperoleh banyak kelas $(K)=7,16 \quad($ pembulatan 7$)$, Range $=43,00$ nilai rata-rata (mean) diperoleh 118,98, medien 118,00 dan standar deviasi 10,68.

Pencarian tingkat kategori variabel Supervisi Pengajaran Agama Hindu Sekolah Dasar seKecamatan Penebel dilakukan dengan terlebih dahulu menghitung mean ideal $\left(\mathrm{M}_{\mathrm{i}}\right)$ dan standar deviasi ideal $\left(\mathrm{Sd}_{\mathrm{i}}\right) . \mathrm{Mi}=1 / 2 \mathrm{x}$ (skor maksimal ideal + skor minimal ideal) $=1 / 2 \times(165+33)=99 . \mathrm{SD}_{\mathrm{i}}=1 / 6 \mathrm{x}$ (skor maksimal ideal - skor minimal ideal $)=1 / 6 \times(165-33)=22$. 
Berdasarkan hasil perhitungan $\mathrm{M}_{\mathrm{i}}$ dan $\mathrm{SD}_{\mathrm{i}}$ didapat $\mathrm{M}_{\mathrm{i}}+3,0 \mathrm{SD}_{\mathrm{i}}=99+$ $3(22)=165 ; \mathrm{M}_{\mathrm{i}}+1,5 \mathrm{SD}_{\mathrm{i}}=99+$ $1,5(22)=132 ; \mathrm{M}_{\mathrm{i}}+0,5 \mathrm{SD}_{\mathrm{i}}=99+$ $0,5(22)=110 ; \mathrm{M}_{\mathrm{i}}-0,5 \mathrm{SD}_{\mathrm{i}}=99-$ $0,5(22)=88 ; \mathrm{M}_{\mathrm{i}}-1,5 \mathrm{SD}_{\mathrm{i}}=99-$ $1,5(22)=66 ;$ dan $\mathrm{M}_{\mathrm{i}}-3, \mathrm{OSD}_{\mathrm{i}}=93-$ $3(22)=33$. Berdasarkan hasil perhitungan tersebut selanjutnya disusun klasifikasi tingkat kategori variabel Supervisi Pengajaran Agama Hindu pada Guru Agama Hindu yang bersertifikat Pendidik di Sekolah Dasar se- Kecamatan Penebel seperti berikut.

Kategori Variabel Supervisi Pengajaran Guru Agama Hindu (X1)

Berdasarkan hasil perhitungan, dapat disimpulkan bahwa variabel Supervisi Pengajaran Pendidikan Guru Agama Hindu yang bersertifikat Pendidik di Sekolah Dasar se- Kecamatan Penebel cenderung berada pada kategori baik sebanyak 31 responden atau sebesar $67,3 \%$, sisanya berada pada kategori sangat baik sebanyak 6 responden atau $13,1 \%$, berada pada kategori cukup sebanyak 9 responden atau $19,6 \%$.

Berdasarkan

analisis hubungan langsung pada blok 2 sesuai dengan koefisien jalur dapat ditafsirkan hasil pengolahan dengan memerhatikan koefisien regresi terstandar, yaitu beta (b) yang dalam analisis jalur berfungsi sebagai koefisien jalur diketahui py1 yang merupakan koefisien hubungan secara langsung Supervisi Pengajaran Agama Hindu $\left(\mathrm{X}_{1}\right)$ dengan kinerja guru Agama Hindu (Y) digambarkan dengan nilai $\mathrm{T}_{\text {hitung }}$ sebesar 2,547 lebih besar dari pada nilai $\mathrm{T}_{\text {tabel }}$ sebesar 1,684. Di samping itu, koefisien beta sebesar 0,013 dengan $\mathrm{p}$ (probabilitas) untuk menunjukkan taraf signifikansi tiap koefisien jalur yang bersangkutan sebesar 0,05 dan nilai $p$ hasil analisis sebesar 0,000. Karena p hasil analisis lebih kecil dari 0,05, maka $\mathrm{H}_{0}$ ditolak dan $\mathrm{H}_{\mathrm{a}}$ diterima. Dengan demikian, ada hubungan langsung supervisi pengajaran guru dengan Kinerja Guru Agama Hindu yang bersertifikat Pendidik di Sekolah Dasar se- Kecamatan Penebel . Artinya, semakin tinggi Supervisi Pengajaran Agama Hindu, maka makin tinggi Kinerja Guru Agama Hindu yang bersertifikat Pendidik di Sekolah Dasar se- Kecamatan Penebel.

\begin{tabular}{|c|c|c|c|l|}
\hline No & $\begin{array}{c}\text { Kelas } \\
\text { Interval }\end{array}$ & Frekuensi & $\begin{array}{c}\text { Persenta } \\
\text { se }\end{array}$ & Kategori \\
\hline 1. & $132-165$ & 6 & $13,1 \%$ & $\begin{array}{l}\text { Sangat } \\
\text { baik }\end{array}$ \\
\hline 2. & $110-131$ & 31 & $67,3 \%$ & Baik \\
\hline 3. & $88-109$ & 9 & $19,6 \%$ & Cukup \\
\hline 4. & $66-87$ & - & - & $\begin{array}{l}\text { Tidak } \\
\text { Baik }\end{array}$ \\
\hline 5 & $33-65$ & - & - & $\begin{array}{l}\text { Sangat } \\
\text { Tidak } \\
\text { Baik }\end{array}$ \\
\hline & & 46 & $100,0 \%$ & \\
\hline
\end{tabular}

\section{Deskriptif Data Hasil Penelitian}

Paparan pembahasan yang berhubungan dengan analisis deskriptif dengan menentukan nilai rata-rata dari hasil pengukuran untuk tiap-tiap variabel untuk menentukan tingkat kategori variabel penelitian.

Berdasarkan pengolahan data, ditemukan bahwa Variabel kinerja guru Agama Hindu di Kecamatan Penebel cenderung berada pada 
kategori sangat baik sebanyak 1 responden atau sebesar $2,2 \%$; berada pada kategori baik sebanyak 37 responden atau $80,4 \%$, dan berada kategori cukup sebanyak 8 responden atau $17,4 \%$. Data empiris hasil penelitian ini ditunjang dengan variabel-variabel yang menunjang Kinerja Guru Agama Hindu yang bersertifikat Pendidik di Sekolah Dasar se- Kecamatan Penebel juga kecenderungan sangat baik.

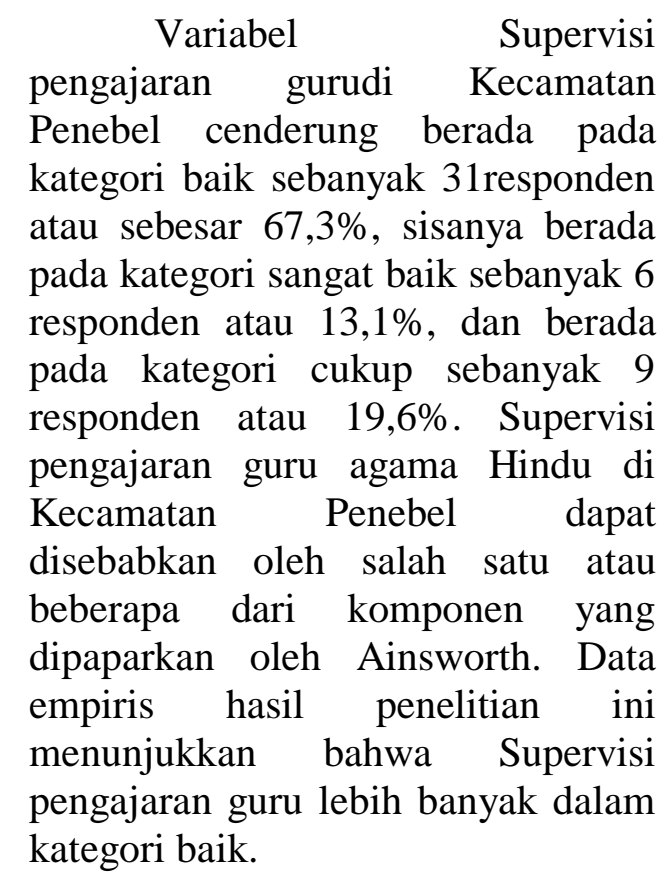

Hubungan Secara Langsung Supervisi Pengajaran Agama Hindu dengan Kinerja Guru Agama Hindu yang bersertifikat pendidik di Sekolah Dasar seKecamatan Penebel

Hasil analisis data menunjukkan bahwa ada hubungan secara langsung Supervisi pengajaran guru dengan kinerja guru Agama Hindu di Kecamatan Penebel. Dengan nilai koefisien jalur dapat ditafsirkan hasil pengolahan dengan memerhatikan koefisien regresi terstandar, yaitu beta (b) yang dalam analisis jalur berfungsi sebagai koefisien jalur diketahui py1 yang merupakan koefisien hubungan secara langsung Supervisi pengajaran Pengajaran Agama Hindu (X) dengan kinerja guru agama Hindu yang bersertifikat Pendidik diSekolah Dasar se-Kabupaten Penebel (Y) digambarkan dengan koefisien regresi terstandar sebagai koefisien jalur dengan diperoleh koefisien beta sebesar 0,135 dengan nilai $\mathrm{T}_{\text {hitung }}$ sebesar 2,547 lebih besar dari pada $\mathrm{T}_{\text {tabel }}$ sebesar 1,684. Di samping itu, nilai $\mathrm{p}$ (probabilitas) yang menunjukkan taraf signifikansi sebesar 0,05 dengan nilai $p$ hasil analisis sebesar 0,013. Karena p hasil analisis lebih kecil dari pada 0,05 , maka $\mathrm{H}_{0}$ ditolak dan $\mathrm{H}_{\mathrm{a}}$ diterima. Dengan demikian, ada hubungan langsung Supervisi pengajaran Agama Hindu dengan Kinerja Guru Agama Hindu yang bersertifikat Pendidik di Sekolah Dasar seKecamatan Penebel .

\section{SIMPULAN}

Berdasarkan hasil analisis dan pembahasan hasil penelitian yang telah diuraikan yang dikembangkan dalam bentuk analisis jalur (path analysis) adalah baik atau fit. Hal ini berarti bahwa model hubungan variable Supervisi Pengajaran Agama Hindu dengan kinerja guru Agama Hindu yang bersertifikat Pendidik di Sekolah Dasar se- Kecamatan Penebel berada pada taraf baik, karena seluruh variabel memiliki $r_{\text {hitung }}(0,9)$ lebih tinggi dari pada $r_{\text {tabel }}(0,396)$. Pertama, Kinerja Guru Agama Hindu yang bersertifikat Pendidik di Sekolah Dasar se- Kecamatan Penebel cenderung berada pada kategori baik. Temuan deskriptif ini sangat positif karena sebagian besar guru di lokasi penelitian memiliki tingkat kinerja baik. Kedua, Supervisi pengajaran guru Sekolah 
Dasar se-Kecamatan Penebel cenderung berada pada kategori baik. Temuan deskriptif ini sangat positif karena hubungan Supervisi pengajaran guru Agama Sekolah Dasar di lokasi penelitian sangat kuat untuk mendukung kinerja guru. hubungan Supervisi pengajaran guru Agama Sekolah Dasar di lokasi penelitian sangat kuat untuk mendukung kinerja guru.

\section{DAFTAR PUSTAKA}

Arbi, S.Z., \& Syahrun, S. 1991. Dasar-dasar Kependidikan. Jakarta: Proyek Pembangunan Lembaga Pendidikan Tenaga Kependidikan Direktorat Jenderal Pendidikan Tinggi Departemen Pendidikan dan Kebudayaan.

Asher, H.B. 1983. Causal Modeling. 2nd Ed. London: SAGE Publications.

Ary, D.S., Jacobs., C.L., \& Razavieh, A. 1982. Pengantar Penelitian Dalam Pendidikan. Terjemahan oleh Arief Furchan. Surabaya: Usaha Nasional.

Azwar, Saifuddin, 1995. Sikap Manusia dan Pengukurannya. Yogyakarta: Pustaka Pelajar

Baso, H.M. 1998. Peran dan Fungsi

Profesional Pengembangan Sumber Daya Manusia. Pelatih \& Kinerja. Hlm. 1 - 2.

Bower Gordon H. Dan Ernest R. Hilgard, 1981. Teories of
http://ejournal.ihdn.ac.id/index.php/AW

Learning.

London:

Prentice-Hall International Inc

Biro Hukum dan Organisasi, Setjen Depdiknas, 2005b. Undang-Undang No.14 Tahun 2005. Tentang Guru dan Dosen. Jakarta

Bernaidan, H. John \& Russel, Joyce E.A. 1995.Human Resources Management. McGraw Hill, Inc.: Singapore

Buford Jr., James., \& Bedeian, A.G. 1988. Management in Extention. (2rd Edition). Alabama: Alabama Cooverative Extention Service, Auburn University

Chan, Sam M, Sam, Tuti T. Sam, $2005 . \quad$ Kebijakan

Pendidikan Era Otonomi Daerah, Jakrta: PT Rajda Grafindo Persada

Collins, Cobuild, 1987. English Language Dictionary. Grat Britain: William Collins Sons \& Co. Ltd, Glasgow

Depdikbud, 1999,Kreatifitas dan Prestasi dalam Pendidikan. Jakarta : Direktorat Jendral Pendidikan Dasar dan Menengah.

Depdiknas, 2006. Rencana Strategi Depdiknas 2005-2006. Jakarta : Balitbang Depdiknas.

Depdiknas, 2005. Standar Nasional

Pendidikan ( SNP)

Peraturan Pemerintah

Nomor: 10 tahun 2005.

Bandung : Fokus Media. 